\title{
Integrating Communications into Engineering Courses: Dimensions of a New Paradigm
}

\author{
Steven Youra \\ Cornell University
}

Engineering students must develop the ability to communicate effectively. To address this need, a growing number of engineering programs are integrating communications into technical coursework. Writing and other forms of presentation can be central to engineering education for both pragmatic and conceptual reasons: (1) The ability to communicate effectively is crucial to the success of engineering projects and careers, and (2) Language is a powerful instrument for learning. As William Zinsser notes, "Writing is how we think our way into a subject and make it our own. Writing enables us to find out what we know-and don't know-about whatever we're trying to learn."1 This presentation examines a variety of creative and successful strategies for incorporating written, oral, and visual communications into engineering classes. It discusses how engineering and writing/communications teachers can collaborate in helping students to master simultaneously the technical subject matter and communications tasks. This talk also assesses potential obstacles to an integrated approach.

Although communications exercises and instruction can enhance teaching and learning, how can engineering teachers effectively integrate writing and speaking into their courses, when those courses seem so remote from English and freshman composition? Drawing upon ten years of work at Cornell University, this presentation will address this and related questions:

- How can informal writing assignments promote active learning and collaborative problemsolving?

- How can communications in workplace settings provide effective models for writing instruction and assignments?

- How can writing exercises be sequenced to guide students' thinking processes (e.g., generating and testing ideas, organizing information and concepts, interpreting data, formulating logical arguments and conclusions)?

- How can engineering teachers respond to writing and oral presentations effectively and efficiently?

- How can students' writing provide useful feedback about teaching and learning in technical courses?

- How can new approaches to communications instruction help engineering schools to meet ABET 2000?

- What are the potential obstacles to integrating communications and how might they be addressed?

To engage these questions, the presentation will review the importance of communications to practicing engineers and consider typical writing tasks at work and in school. That discussion will provide a framework for examining a range of sample communications assignments and instructional approaches developed for technical courses at Cornell and elsewhere. These assignments will illustrate strategies for integrating writing and oral presentation into technical courses and will highlight potential opportunities for and limits to integrating communications across an engineering curriculum. 
1. Zinsser, W. 1988. Writing to learn. NY: Harper \& Row. p 16.

Steven Youra is Robert N. Noyce Director of the Engineering Communications Program and adjunct professor of English at Cornell. He has lectured widely and published articles on technical writing, computers and composition, writing across the curriculum, American literature, and film. He also consults to industry on communications issues. 